\title{
Enhancement of phagocytotic activity by prion protein in PrP-deficient macrophage cells
}

\author{
RYUTA URAKI $^{1}$, AKIKAZU SAKUDO ${ }^{2}$, SAEKO ANDO $^{1}$, HIROSHI KITANI $^{3}$ and TAKASHI ONODERA ${ }^{1}$ \\ ${ }^{1}$ Department of Molecular Immunology, School of Agricultural and Life Sciences, University of Tokyo, Bunkyo-ku \\ Yayoi 1-1-1, Tokyo 113-8657; ${ }^{2}$ Laboratory of Biometabolic Chemistry, School of Health Sciences, Faculty of Medicine, \\ University of the Ryukyus, 207 Uehara, Nishihara, Okinawa 903-0215; ${ }^{3}$ Transgenic Animal Research Center, \\ National Institute of Agrobiological Sciences, Ohwashi 1-2, Tsukuba, Ibaraki 305-8634, Japan
}

Received June 16, 2010; Accepted July 23, 2010

DOI: 10.3892/ijmm_00000495

\begin{abstract}
Macrophages, especially follicular dendritic cells, contribute to the pathogenesis of prion diseases by accumulating an abnormal isoform of prion protein $\left(\mathrm{PrPsc}^{\mathrm{sc}}\right)$, which is converted from the cellular isoform of prion protein $\left(\mathrm{PrP}^{\mathrm{C}}\right)$. As information on the function of $\operatorname{PrP}^{\mathrm{C}}$ in macrophages is limited, we have established a prion protein (PrP) gene (Prnp)deficient macrophage cell line from the bone marrow of $\mathrm{ZrchI}$ Prnp $^{-/}$mice. These cells expressed macrophage specific proteins (F4/80 and MOMA-2) and displayed phagocytotic properties. The $\mathrm{Prnp}^{-/-}$macrophage cell line (MplZ) showed shorter pseudopodium extension and less phagocytotic activity than a $\mathrm{Prnp}^{+/+}$macrophage cell line (MWF). In addition, the $\mathrm{MplZ}$ cells were more sensitive to serum deprivation than the MWF cells and underwent apoptotic cell death in these conditions. These findings suggest that $\mathrm{PrP}^{\mathrm{C}}$ enhances the incorporation of materials possibly including $\mathrm{PrP}^{\mathrm{Sc}}$ and decreases the sensitivity of cells to oxidative stress, which may be induced by $\operatorname{PrP}^{\mathrm{Sc}}$ accumulation.
\end{abstract}

\section{Introduction}

Prion diseases, which are also called transmissible spongiform encephalopathies (TSE), are fatal neurodegenerative diseases, a number of which are caused by oral contamination with an infectious agent. The agent is thought to be a misfolded form [scrapie associated prion protein $\left(\mathrm{PrP}^{\mathrm{Sc}}\right)$ ] of a normal host protein [the cellular isoform of prion protein $\left(\mathrm{PrP}^{\mathrm{C}}\right)$ ]. These diseases are characterized by the deposition of $\operatorname{PrP}^{\mathrm{Sc}}$ within the brain. While the precise nature of the agent is still unclear, $\mathrm{PrPS}^{\mathrm{Sc}}$ is considered to be a major constituent of the infectious agent purified from the diseased brain (1). Prion protein (PrP)

Correspondence to: Professor Takashi Onodera, Department of Molecular Immunology, School of Agricultural and Life Sciences, University of Tokyo, Bunkyo-ku Yayoi 1-1-1, Tokyo 113-8657, Japan

E-mail: aonoder@mail.ecc.u-tokyo.ac.jp

Key words: $\mathrm{PrP}^{\mathrm{C}}$, phagocytotic activity, pseudopodium gene (Prnp)-deficient mice are not susceptible to prion diseases, demonstrating that cellular prion protein $\left(\mathrm{PrP}^{\mathrm{C}}\right)$ is required for disease development $(2,3)$. Therefore, it is important to characterize the functions of $\mathrm{PrP}^{\mathrm{C}}$ and the mechanisms behind the conversion of $\operatorname{PrP}^{\mathrm{C}}$ to $\mathrm{PrP}^{\mathrm{Sc}}$ in order to understand the infectious etiology of this disease.

Prions accumulate not only in the central nervous system but also in a wide variety of peripheral tissues and cells including lymphoid organs (4-6). Most cases of infectious prion disease seem to be initiated by peripheral invasion, and dissemination of the infectious agent is likely to involve $\mathrm{PrP}^{\mathrm{Sc}}$ replication in lymphoid organs and transmission by peripheral nerves (7). Recent studies have shown that cells of the immune system, such as macrophages, dendritic cells (DC), and lymphocytes, may act as replication sites or reservoirs for prions (8). Although how and when $\mathrm{PrP}^{\mathrm{Sc}}$ are acquired during the course of a natural infection remains unclear, evidence is gradually emerging. After experimental intragastric or oral exposure of rodents to scrapie, infectivity and $\mathrm{PrP}^{\mathrm{Sc}}$ accumulate in Peyer's patches, gut-associated lymphoid tissues (GALT) and the ganglia of the enteric nervous system $(9,10)$ long before their detection in the central nervous system (CNS) (11). Follicular dendritic cells (FDC) in the germinal centers of lymphoid organs are reported to be sites of $\operatorname{PrP}^{\mathrm{Sc}}$ accumulation $(8,12,13)$. The transport mechanisms by which transmissible spongiform encephalopathy (TSE) agents reach the germinal centers from the gut lumen are not known, but once it has passed across the intestinal epithelium, current data suggest that the TSE agent is acquired by migratory DC and macrophages (14). Although the precise involvement of macrophages in TSE pathogenesis is uncertain, macrophages may play roles in its pathogenesis, such as TSE agent transportation or propagation.

Reports on the relationship between $\mathrm{PrP}^{\mathrm{C}}$ expression and the phagocytotic ability of macrophages have suggested that $\mathrm{PrP}^{\mathrm{C}}$ is a negative modulator of phagocytosis and that $\operatorname{PrP}^{\mathrm{C}}$ plays important roles in normal macrophage function as well as the pathogenesis of prion diseases (15). Although it is inconsistent with previous reports, we have shown that $\mathrm{PrP}^{\mathrm{C}}$ expression enhanced the phagocytotic activity of Prnpdeficient macrophage cell lines established from Prnp-deficient mice. 


\section{Materials and methods}

Experimental animals and preparation of mouse bone marrowderived macrophages (BMM). ZrchI Prnp ${ }^{-/}$(16) mice were used in the experiments, and $\mathrm{FVB} / \mathrm{N}$ mice were used as the wild-type mice. The ZrchI mice were housed in specific pathogen-free (SPF) conditions under an alternating 14/10 h light/dark cycle. The animals were given free access to standard laboratory food (Japan CLEA, Tokyo, Japan). BMM were generated from bone marrow precursors, as previously described (17) with some modifications. Bone marrow cells obtained from the femurs and tibiae of 6- to 8 -week-old mice were suspended in $\alpha$-minimum essential medium (MEM; Gibco) supplemented with $10 \%$ fetal calf serum (FCS) in $60-\mathrm{mm}$ dishes for $16 \mathrm{~h}$ in the presence of macrophage colony-stimulating factor (M-CSF) $(10 \mathrm{ng} / \mathrm{ml})$ (Sigma, Germany). Then, the non-adherent cells were harvested and cultured for 2 days with M-CSF (10 ng/ml), before the remaining non-adherent cells were removed from the cultures by pipetting. The adherent cells were used as BMM. The BMM were incubated for a further 4 days with M-CSF (10 ng/ml) and used for the experiments.

Immortalization of BMM. $\Psi 2$ (18) cells were used to produce a replication-defective retrovirus encoding neomycin phosphotransferase and SV40 large T antigen in a pZIP-NeoSV(X)1 backbone (19). The cells were plated at a concentration of $4 \times 10^{6}$ cells per $90-\mathrm{mm}$ dish in Dulbecco's modified Eagle's medium (DMEM $4500 \mathrm{mg}$ glucose/l) (Sigma) with 10\% FCS, 12-24 h before transfection. Medium containing the virus was used to infect the target cells.

The BMM were infected for $24 \mathrm{~h}$ with filtered medium containing virus particles in the presence of $8 \mu \mathrm{g} / \mathrm{ml}$ polybrene (Sigma) and M-CSF (10 ng/ml). The infected cells were selected with $400 \mu \mathrm{g} / \mathrm{ml} \mathrm{G} 418$ (Wako, Osaka, Japan) and M-CSF $(10 \mathrm{ng} / \mathrm{ml})$ for $>7$ days. Then, individual colonies were isolated and transferred into separate wells.

Cell culture. ZrchI type Prnp ${ }^{-/}$macrophage cells (MplZ) and FVB/N type Prnp $^{+/+}$macrophage cells (MWF) were maintained in Dulbecco's modified Eagle's medium (DMEM $4500 \mathrm{mg}$ glucose/l) with $10 \%$ FCS. All cells were incubated at $37^{\circ} \mathrm{C}$ in a $5 \% \mathrm{CO}_{2}$ atmosphere. The cells were collected with mild trypsinization before confluence and resuspended in growth medium before being replated on dishes.

Indirect immunofluorescence assay (IFA). Cells $\left(5 \times 10^{4}\right)$ were plated on 8-well chamber slides (BD Falcon) supplemented with $10 \%$ FCS. After 24 h, the cells were washed with PBS and fixed with $10 \%$ formalin in PBS for 30 min on ice. After fixation, the cells were washed with PBS and permeabilized using $0.1 \%$ Triton X-100 in PBS. After being blocked with Block-ACE (Dainippon Pharmaceutical, Japan) in PBS for $1 \mathrm{~h}$, the cells were incubated with the primary antibodies for $1 \mathrm{~h}$ at room temperature in a humidified box. The negative controls were incubated without the primary antibodies. Then, the cells were incubated with the secondary antibodies for $1 \mathrm{~h}$ at room temperature in a humidified black box. After rinsing the slides with PBS containing 0.1\% Tween-20 (PBS-T), the immunostained slides were observed under a fluorescence microscope. The primary antibodies were as follows: rat anti-mouse F4/80 antigen monoclonal antibody $(1: 100)$ (AbDSerotec, UK) and rat anti-murine monocyte/ macrophage monoclonal antibody (MOMA-2) (1:100) (Abcam, UK). The secondary antibodies were as follows: Alexa Fluor ${ }^{\circledR} 546$ labeled goat anti-rat IgG $(\mathrm{H}+\mathrm{L})(1: 600)$ (Invitrogen, USA).

DNA polymerase chain reaction (DNA-PCR). DNA extraction was carried out using the same technique as used for the detection of DNA fragments. Then, the extracted DNA was used for PCR with AmpliTaq Gold DNA polymerase (Applied Biosystems) and the following primers: mouse PrP ORF (F) (5'-AGCTCGAGATGGCGAACCTTGGCTACTG-3'), mouse PrP ORF (R) (5'-TCGCGGCCGCTCATCCCACGAT CAGGAAGA-3'), mouse $\beta$-actin (F) (5'-GTTACCAACTGG GACGACA-3'), and mouse $\beta$-actin (R) (5'-TGGCCATCTCC TGCTCGAA-3'). The PCR involved 30 cycles of predenaturation at $94^{\circ} \mathrm{C}$ for $5 \mathrm{~min}$, denaturation at $94^{\circ} \mathrm{C}$ for $30 \mathrm{sec}$, annealing at $65^{\circ} \mathrm{C}$ for $1 \mathrm{~min}$, elongation at $72^{\circ} \mathrm{C}$ for $3 \mathrm{~min}$, and finally elongation at $72^{\circ} \mathrm{C}$ for $7 \mathrm{~min}$. A cellular marker, $\beta$-actin, was used as the control. The PCR products were separated by electrophoresis on a $1 \%$ agarose gel containing ethidium bromide and identified under UV light.

After the PCR products had been extracted from the agarose gel using a QIAEX II Gel Extraction kit (Qiagen), they were reacted with the same primers as used for the PCR using BigDyeRTerminator v1.1/v3.1 (Invitrogen). Then, direct sequencing was carried out with an Applied Biosystems 3130xl genetic analyzer (Applied Biosystems).

Reverse transcription polymerase chain reaction (RT-PCR). RNA was extracted from the cells with TRIzol reagent (Invitrogen) according to the manufacturer's instructions. After the extraction of total RNA, $1.5 \mu \mathrm{g}$ of RNA was reverse transcribed to cDNA with M-MCV Reverse Transcriptase (USB Corp., USA) and random primers. cDNA ( $1 \mu 1)$ was used for PCR together with AmpliTaq Gold DNA polymerase (Applied Biosystems) and the following primers: mouse PrP ORF (F) (5'-AGCTCGAGATGGCGAACCTTGGCTA CTG-3'), mouse PrP ORF (R) (5'-TCGCGGCCGCTCATCC CACGATCAGGAAGA-3'), mouse B-actin (F) (5'-GTTACC AACTGGGACGACA-3'), and mouse $\beta$-actin (R) (5'-TGGC CATCTCCTGCTCGAA-3'). PCR involved 30 cycles of predenaturation at $94^{\circ} \mathrm{C}$ for $5 \mathrm{~min}$, denaturation at $94^{\circ} \mathrm{C}$ for $30 \mathrm{sec}$, annealing at $65^{\circ} \mathrm{C}$ for $1 \mathrm{~min}$, elongation at $72^{\circ} \mathrm{C}$ for $3 \mathrm{~min}$, and finally elongation at $72^{\circ} \mathrm{C}$ for $7 \mathrm{~min}$. A cellular marker, $B$-actin, was used as the control. The PCR products were separated by electrophoresis on a $1 \%$ agarose gel containing ethidium bromide and identified under UV light.

Phagocytosis assay. The uptake of fluorescent latex beads was examined. At first, the macrophage cell lines were plated in 8-well chamber slides $\left(5 \times 10^{4}\right.$ cells per well) for $12-24 \mathrm{~h}$, and then Fluoresbrite ${ }^{\mathrm{TM}}$ Carboxylate YG 1.5 Micron Microspheres (fluorescent latex beads; Polyscience Inc., USA) were added at a 1:1000 dilution in medium. The cells were further incubated for $3 \mathrm{~h}$ at $37^{\circ} \mathrm{C}$ in a humidified $\mathrm{CO}_{2}$ incubator. Following incubation, the cells were washed three times with PBS to remove the uningested fluorescent latex beads that 
had become non-specifically attached to the cell surface. Then, the cells were fixed with $10 \%$ formalin in PBS and labeled with DAPI. The latex beads ingested by the macrophages were observed under a fluorescence microscope after being cultivated for $3 \mathrm{~h}$. The incorporation of the fluorescent latex beads was examined by two approaches. The first was an in vitro phagocytosis assay, which was performed as previously described (20) with some modifications. MWF and MplZ cells were plated on 60-mm dishes. Then, Fluoresbrite Carboxylate YG 1.5 Micron Microspheres (fluorescent latex beads; Polyscience Inc.) were added to $5 \times 10^{6}$ cells (final cell/ bead ratio, 1:10). The cells were then incubated for a further $120 \mathrm{~min}$ at $37^{\circ} \mathrm{C}$ in a humidified $\mathrm{CO}_{2}$ incubator. Following incubation, the cells were washed 5 times with PBS to remove the uningested latex beads that had become non-specifically attached to the cell surface. The phagocytotic ability of the macrophages was examined by fluorescence microscopy. For each assay, a minimum of 150 macrophages was examined on each slide in triplicate, together with the total number of macrophages and ingested beads. In addition, the ratio of the uptake of fluorescent latex beads by the macrophages was also analyzed using a flow cytometer (FACS Calibur; BecktonDickinson, USA). A centrifuge tube was filled with $10^{6}$ cells in $5 \mathrm{ml}$ medium, which were then incubated under mixing with a rotator at $37^{\circ} \mathrm{C}$. After $3 \mathrm{~h}$, the cells were washed with PBS and counted using a flow cytometer.

Measurement of macrophage pseudopodium length. After the two types of macrophages (MWF and MplZ) had been maintained for $24 \mathrm{~h}$ in DMEM (4500 mg glucose/l) with $10 \%$ FCS, the pseudopodium length of the cells was quantified using image analysis software (Scion Image, USA). At least 150 pseudopodia were measured in each cell type.

Observation of apoptosis induced by serum deprivation and the detection of internucleosomal DNA fragmentation. To induce apoptosis, the serum was removed from the culture medium as described previously (21). MWF and MplZ cells were plated in $90-\mathrm{mm}$ culture dishes $\left(5.0 \times 10^{6}\right.$ cells per dish) in DMEM (4500 mg glucose/l) with $10 \% \mathrm{FCS}$ and maintained at $37^{\circ} \mathrm{C}$ in a humidified incubator. One day later, the cells were washed twice with serum-free medium and then placed in fresh serumfree medium. Then, the cells were observed at 0,24 and $48 \mathrm{~h}$. Internucleosomal DNA fragmentation was detected with a DNA fragmentation assay after $24 \mathrm{~h}$ incubation. The cells and culture supernatants were collected and centrifuged at $2000 \mathrm{rpm}$. The resultant pellets were lysed with lysis buffer [10 mM Tris-HCl (pH 7.4), 10 mM EDTA (pH 8.0) and 0.5\% Triton X-100], incubated for $20 \mathrm{~min}$ on ice, and centrifuged at $12000 \mathrm{x} \mathrm{g}$ for $30 \mathrm{~min}$ at $4^{\circ} \mathrm{C}$. The aqueous phase was then incubated with $200 \mu \mathrm{g} / \mathrm{ml}$ DNase-free RNase A (Nippongene, Tokyo, Japan) for $1 \mathrm{~h}$ at $37^{\circ} \mathrm{C}$. Proteins were digested with $200 \mu \mathrm{g} / \mathrm{ml}$ of proteinase $\mathrm{K}$ (PK, Tritirachium, alkaline proteinase, Wako, Tokyo) for $1 \mathrm{~h}$ at $37^{\circ} \mathrm{C}$, and then DNA was precipitated in a solution of $5 \mathrm{M} \mathrm{NaCl}$ in 2-propanol overnight at $-20^{\circ} \mathrm{C}$. The precipitated DNA samples were resuspended in TE buffer [10 mM Tris-HCl (pH 7.4), 1 mM EDTA (pH 8.0)] and electrophoresed on a $2.0 \%$ agarose gel with ethidium bromide $(0.5 \mathrm{mg} / \mathrm{ml})$. DNA bands were visualized using a UV light-transilluminator and photographed.
A

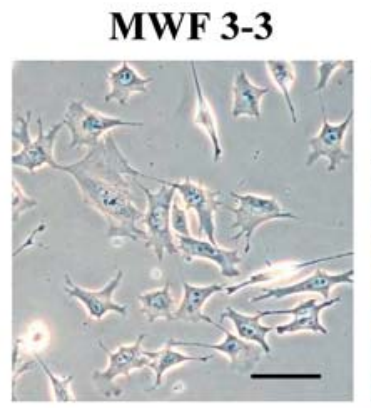

MplZ 4-3

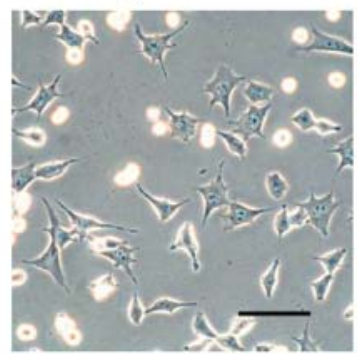

\section{B}
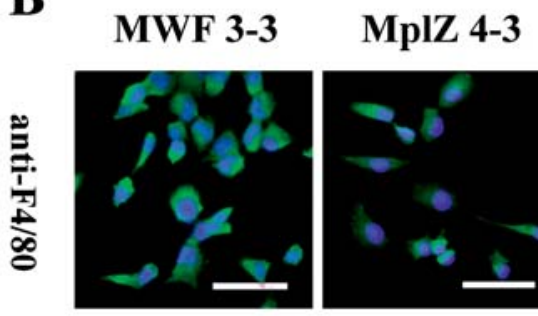

Control
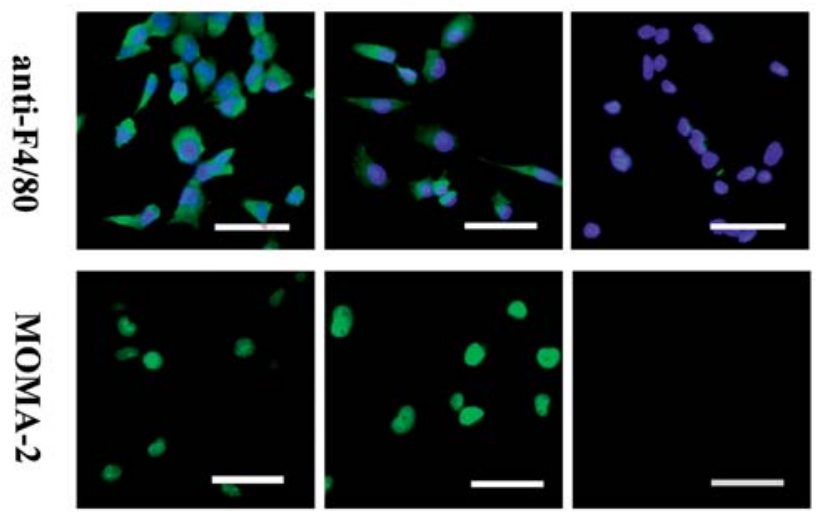

Figure 1. Phase contrast images of macrophage cell lines in medium and their immunocytochemical characterization. (A) Macrophage cell lines derived from FVB/N mice (MWF3-3) and ZrchI Prnp ${ }^{-/}$mice (MplZ4-3) were used in this study. Scale bar, $100 \mu \mathrm{m}$. (B) The cells were fixed and analyzed by IFA with anti-F4/80 or MOMA-2. The negative control (Control) was incubated without primary antibody. Scale bar, $50 \mu \mathrm{m}$.

\section{Results}

Establishment of macrophage cell lines from Prnp ${ }^{+/+}$and Prnp $^{-/}$mice. BMM from FVB/N Prnp ${ }^{+/+}$and Zrch1 Prnp ${ }^{-1}$ mice were transfected with SV40 large $\mathrm{T}$ and selected with $400 \mu \mathrm{g} / \mathrm{ml} \mathrm{G} 418$. In total, $4 \mathrm{MplZ}$ and $5 \mathrm{MWF}$ cell lines were established. Among the obtained clones, we focused on MWF3-3 (from FVB/N mice) and MplZ4-3 (from Zrch1 Prnp $^{-/-}$mice) (Fig. 1A). The morphological characteristics of these cell lines were similar to those of primary macrophages (20). MWF3-3 and Mpl4-3 expressed F4/80 and MOMA2 (Fig. 1B), but did not express Mac-1 (data not shown). A genotyping test with mouse PrP ORF primers was performed to confirm the presence or absence of the Prnp gene in DNA extracted from the MWF3-3 and MplZ4-3 cells. PCR analysis showed a band related to the Prnp gene in the MWF3-3 cells, whereas no such band was detected in the MplZ4-3 cells (Fig. 2A). Next, total RNA was extracted from the wild-type cell line (MWF3-3). RT-PCR analysis with mouse PrP ORF primers was carried out to confirm the expression of PrP, and the relevant band was detected in the MWF3-3 cells (Fig. 2B). $B$-actin was included as an internal control in both the DNA-PCR and RT-PCR experiments. As a result of DNA sequencing, the PCR products were found to be consistent with each predicted sequence (Genbank accession no.: U29186 for PrP and BC138614 for ß-actin). 
A

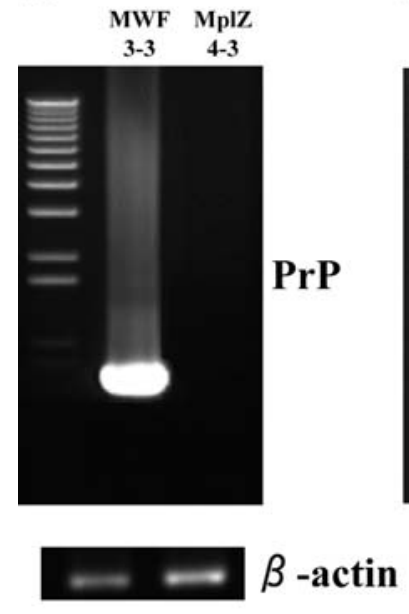

DNA-PCR
B

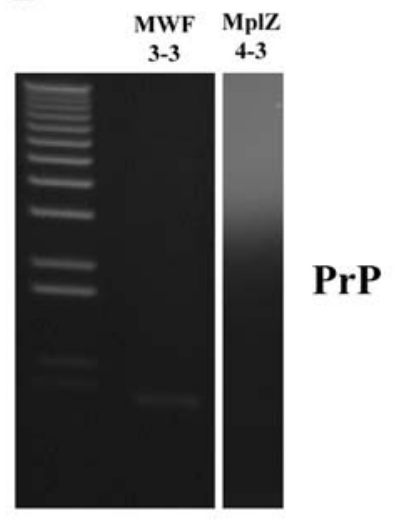

RT-PCR

Figure 2. The confirmation of prion protein gene disruption in the MplZ4-3 cell line. (A) The absence and presence of Prnp in macrophages from FVB/ $\mathrm{N}$ mice (MWF3-3) and ZrchI Prnp ${ }^{-/}$mice (MplZ4-3), respectively, was confirmed by DNA PCR using mouse PrP ORF primers. (B) RT-PCR analysis showed PrP expression in the MWF3-3 cells.

Decreased phagocytotic activity in MplZ cells. In the macrophage cell lines produced from the Prnp ${ }^{+/+}$and Prnp ${ }^{-/}$mice, the incorporation of latex beads was observed, which confirmed that the cells maintained the ability to perform phagocytosis (Fig. 3A). Then, the phagocytotic activity of the MplZ4-3 cells was compared to that of the MWF3-3 cells using two approaches. The macrophages were incubated for $2 \mathrm{~h}$ with fluorescent latex beads, and phagocytotic capacity was assessed by counting the number of phagocytotic cells and ingested beads and then calculating the phagocytotic index (PI) $(\mathrm{PI}=$ percentage of phagocytotic cells containing $>1$ bead $\mathrm{x}$ mean number of beads in the phagocytotic cells containing beads). The percentage of MWF3-3 cells containing beads was significantly higher than that for MplZ4-3 cells.

However, there was no significant difference in the mean number of beads per cell or the PI between the MplZ and MWF cells (Fig. 3B). The phagocytotic rates of the MWF3-3 and MplZ4-3 cells were also analyzed by flow cytometry. As a result, we found that the rate of phagocytosis of the MWF3-3 cells was significantly higher than that of the MplZ4-3 cells (Fig. 3C). These results suggested that PrP regulates phagocytosis.

Morphological changes in MWF and MplZ cells. The MplZ4-3 cells included a higher number of detached cells than the MWF3-3 cells. More interestingly, the pseudopodia of the MplZ4-3 cells were significantly shorter than those of the MWF cells (the mean value for MplZ4-3 cells was $\sim 17.48 \mu \mathrm{m}$, while that for MWF cells was $23.01 \mu \mathrm{m}$ ) (Fig. 4). A similar tendency was also observed in other MWF and MplZ cell lines. These data coincide with the findings of a previous study that showed that the pseudopodia of peritoneal macrophages derived from Prnp $^{-/}$mice were shorter than those of macro-phages derived from wild-type mice (20).

MplZ cells underwent apoptosis after serum deprivation. The death of MplZ4-3 cells was observed after serum deprivation, whereas few MWF3-3 cells died under the same conditions (Fig. 5A). Therefore, to investigate whether these cell deaths were due to apoptosis or necrosis, a DNA fragmentation assay was performed. DNA ladders were detected $24 \mathrm{~h}$ after serum withdrawal. At $24 \mathrm{~h}$, the DNA ladder of the MplZ4-3 cells was stronger than that of the MWF3-3 cells. On the other hand, no DNA ladders were detected for either cell line cultured in $10 \%$ FCS (Fig. 5B). This observation was consistent with the findings of a previous study $(20,22)$ and indicated that $\operatorname{PrP}^{\mathrm{C}}$ suppresses apoptosis in macrophages.

\section{Discussion}

Previously, Prnp-deficient neuronal and astroglial cell lines were established. Using these cell lines, we have shown that $\mathrm{PrPC}^{\mathrm{C}}$ has anti-oxidative and neuroprotective properties $(21,23)$.
A
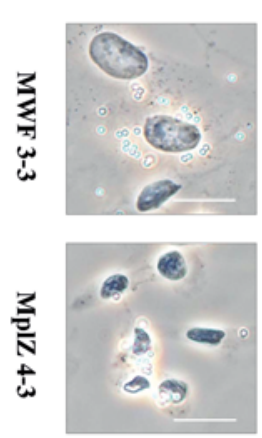

B
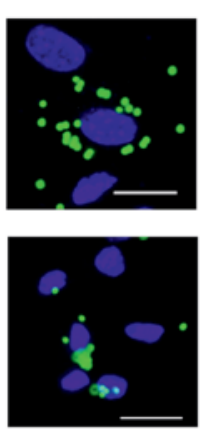

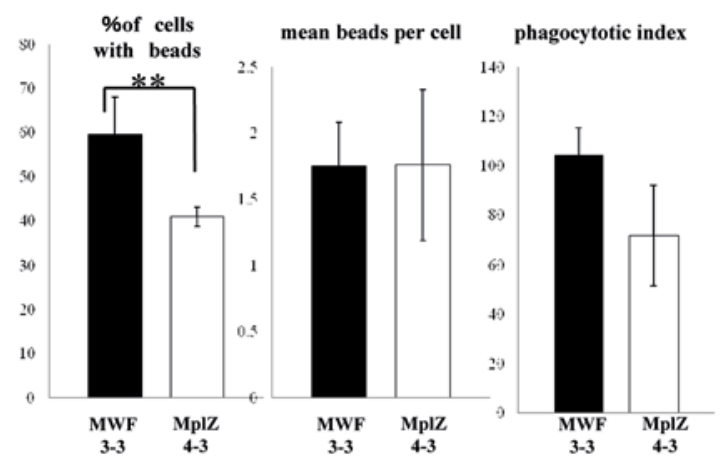

C

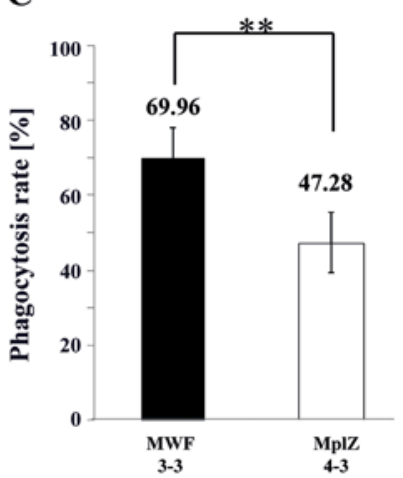

Figure 3. The phagocytotic activity of MWF3-3 and MplZ4-3 cells. (A) The morphologies of macrophages of each cell line are shown together with latex beads in the same field on left and right side, respectively, under phase contrast microscopy. The ability to perform phagocytosis was confirmed by the uptake of latex beads (green). DAPI was used to stain the cell nuclei (blue). Scale bar, $10 \mu \mathrm{m}$. (B) The phagocytotic activity of the MplZ4-3 cells was compared to that of the MWF3-3 cells. The macrophages were incubated for $2 \mathrm{~h}$ with fluorescent latex beads. The percentage of phagocytotic cells containing beads and the mean number of beads per cell were counted, and the phagocytotic index (percentage of phagocytotic cells containing beads $\mathrm{x}$ mean number of beads in the phagocytotic cells containing beads) is shown. The percentage of MWF3-3 phagocytotic cells containing beads was significantly higher than that for MplZ4-3 cells. Values represent the mean \pm SD of triplicate assays. (C) The phagocytosis rate was also higher in the MWF3-3 cells than in the MplZ4-3 cells according to flow cytometry analysis, as described in Materials and methods. Statistical differences were determined using the Student's t-test. ${ }^{* *} \mathrm{P}<0.01$. 


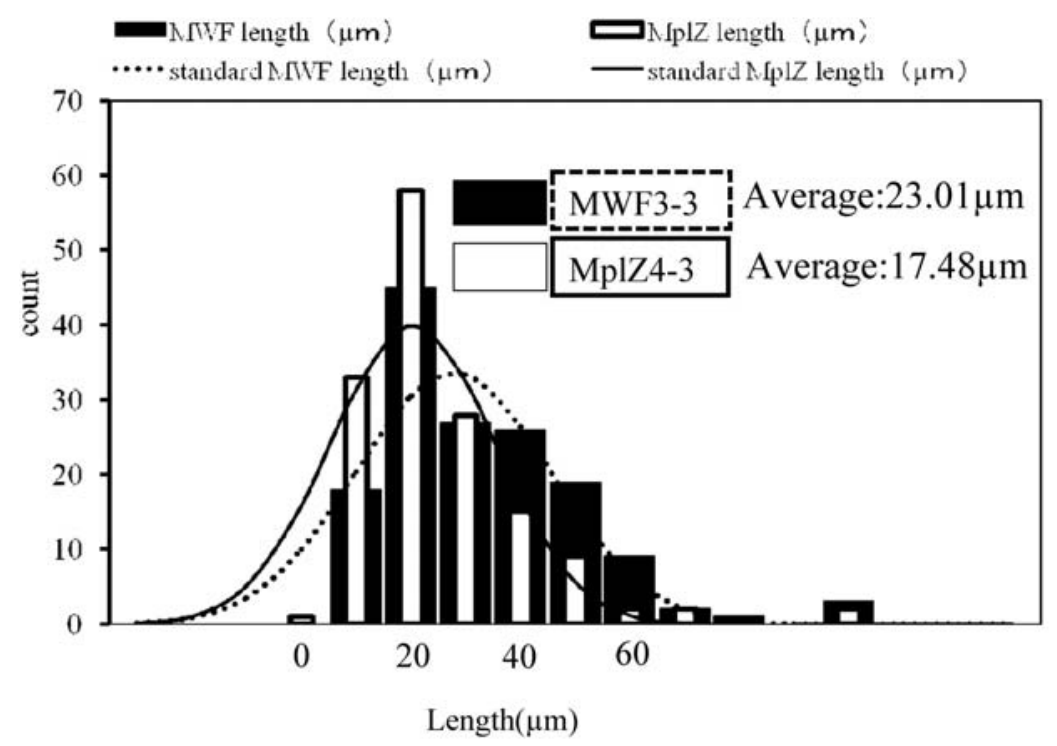

Figure 4. The pseudopodium lengths of MWF3-3 and MplZ4-3 cells. The pseudopodium lengths of the cells were quantified using image analysis software (Scion Image). At least 150 pseudopodia were measured for both MWF3-3 and MplZ4-3 cells. The mean pseodopodium length was 23.01 $\mu$ m in the MWF3-3 cells and $17.48 \mu \mathrm{m}$ in the MplZ4-3 cells. The mean pseudopodium length of the MplZ4-3 cells was significantly shorter than that of the MWF3-3 cells.

$\mathbf{A}$

(
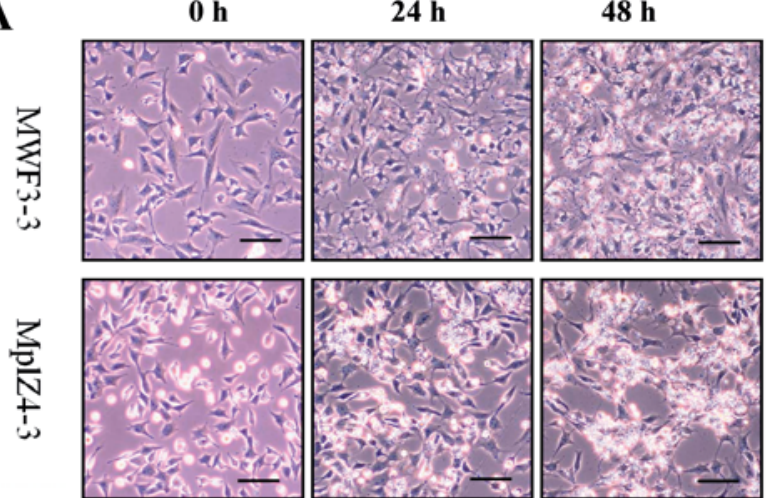

B
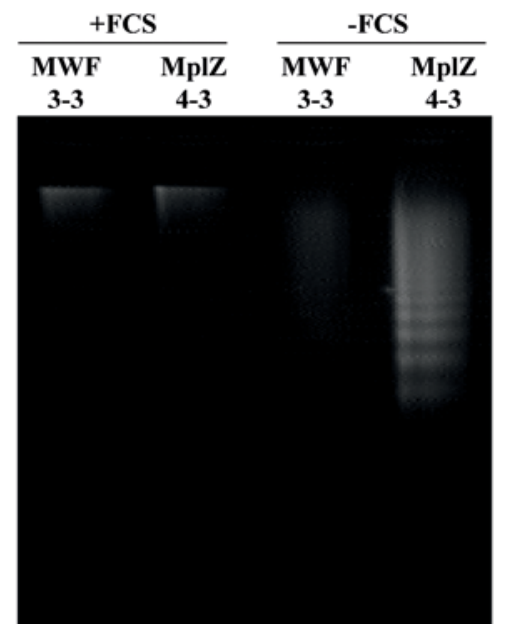

Figure 5. Morphological appearance of MWF3-3 and MplZ4-3 cells, after 0, 24 and $48 \mathrm{~h}$ incubation in serum-free medium. (A) The cells were plated at $5 \times 10^{5}$ cells in 60 -mm dishes. After serum deprivation for $24 \mathrm{~h}$, some of the Prnp $^{-/}$cells (MplZ4-3) had undergone cell death and demonstrated round, condensed and irregularly shaped cell bodies. The Prnp ${ }^{+/+}$cells (MWF3-3) continued growing and showed few morphological changes under serumfree conditions. Scale bar, $100 \mu \mathrm{m}$. (B) DNA fragmentation of MWF3-3 and MplZ4-3 after $24 \mathrm{~h}$ serum withdrawal. DNA ladders, which represent cell apoptosis, were detected in the assay for MplZ4-3 cells. On the other hand, no DNA ladders were detected when the cells were cultured in the presence of $10 \%$ FCS
In this study, Prnp-deficient a macrophage cell line was established from ZrchI Prnp ${ }^{-/}$mice. As FDC and macrophages may be associated with $\mathrm{PrP}^{\mathrm{Sc}}$ infection and proliferation, these cells can be used for future studies of the function of $\operatorname{PrP}^{\mathrm{C}}$ and prion disease. The Prnp-deficient (MplZ) and wildtype cells (MWF) established in the present study expressed macrophage specific markers and exhibited phagocytosis. Although, these cell lines showed the same characteristics in an IFA, the phagocytotic activity and pseudopodia length of the MplZ cells were decreased compared to those of the MFW cells. However, it was reported that resident peritoneal macrophage cells from Prnp $^{-/}$mice phagocytosed at a higher rate than Prnp ${ }^{+/+}$cells in vitro (24), suggesting that $\operatorname{PrP}^{\mathrm{C}}$ is a negative modulator of phagocytosis. In contrast, our results showed that Prnp $^{-/}$cells phagocytosed at a lower rate than Prnp $^{+/+}$cells. One possible explanation for this discrepancy is the different mouse strains used. Whereas the previous report examined primary cells derived from C57BL/6, we used a macrophage cell line derived from FVB/N.

As another explanation, $\mathrm{PrPC}^{\mathrm{C}}$ is thought to be associated with cell adherence (25), suggesting that the wild-type cells were attached to the dishes more strongly than the Prnp ${ }^{-/}$ cells, thus allowing them to produce longer pseudopodia than the ZrchI Prnp ${ }^{-/}$macrophage cells. In a previous study (20), the cells used were derived from Rikn PrP-gene-deficient mice, which ectopically produce Doppel. So, the effects of Doppel may be also related to the above phenomena. Taken together, $\mathrm{PrP}^{\mathrm{C}}$ may play an important role in the incorporation of materials, possibly including $\mathrm{PrPs}^{\mathrm{Sc}}$, into cells. These features may be related to the pathogenesis of prion diseases. Further studies are necessary to understand the role of $\mathrm{PrP}^{\mathrm{C}}$ in macrophages under normal and pathological conditions.

$\operatorname{PrP}^{\mathrm{C}}$ is localized not only in the brain, but also in the peripheral tissues and cells including immunocompetent cells. It was previously reported that Prnp-deficient neuronal and astroglial cells are sensitive to oxidative stress in serumfree conditions $(21,23)$. Previous studies have suggested that 
$\mathrm{PrP}^{\mathrm{C}}$ plays a role in inducing the expression of proteins that are active against oxidative stress or that $\mathrm{PrP}^{\mathrm{C}}$ itself acts as an anti-oxidant protein. More importantly, $\operatorname{PrP}^{\mathrm{Sc}}$ accumulation induces increased oxidative stress. This indicates that ZrchI Prnp $^{-/}$macrophage cells are more sensitive to the oxidative stress induced by serum withdrawal than $\mathrm{Prnp}^{+/+}$cells, suggesting that $\mathrm{PrP}^{\mathrm{C}}$ increases the survival rate of macrophages as well as neuronal and astroglial cells and contributes to the delivery of $\operatorname{PrP}^{S c}$ via macrophages. Finally, the current study emphasizes that the established macrophage cell lines would be useful tools for a wide range of studies in the field of prion biology.

\section{Acknowledgements}

This study was supported by Grants-in-aid from the Research Committee of Prion Disease and Slow Virus Infection of the Ministry of Health, Labour, and Welfare of Japan.

\section{References}

1. Prusiner SB: Research on scrapie. Lancet 2: 494-495, 1982.

2. Büeler H, Aguzzi A, Sailer A, et al: Mice devoid of PrP are resistant to scrapie. Cell 73: 1339-1347, 1993.

3. Manson JC, Clarke AR, Hooper ML, et al: 129/Ola mice carrying a null mutation in PrP that abolishes mRNA production are developmentally normal. Mol Neurobiol 8: 121-127, 1994.

4. Fournier JG: Non-neuronal cellular prion protein. Int Rev Cytol 208: 121-160, 2001

5. Burthem J, Urban B, Pain A and Roberts DJ: The normal cellular prion protein is strongly expressed by myeloid dendritic cells. Blood 98: 3733-3738, 2001.

6. Krebs B, Dorner-Ciossek C, Schmalzbauer R, et al: Prion protein induced signaling cascades in monocytes. Biochem Biophys Res Commun 340: 13-22, 2006.

7. Race R, Oldstone M and Chesebro B: Entry versus blockade of brain infection following oral or intraperitoneal scrapie administration: role of prion protein expression in peripheral nerves and spleen. J Virol 74: 828-833, 2000.

8. Aucouturier $\mathrm{P}$ and Carnaud $\mathrm{C}$ : The immune system and prion diseases: a relationship of complicity and blindness. J Leukoc Biol 72: 1075-1083, 2002.

9. Kimberlin RH and Walker CA: Pathogenesis of scrapie in mice after intragastric infection. Virus Res 12: 213-220, 1989.

10. Beekes M and McBride PA: Early accumulation of pathological PrP in the enteric nervous system and gut-associated lymphoid tissue of hamsters orally infected with scrapie. Neurosci Lett 278: 181-184, 2000
11. Mabbott NA and MacPherson GG: Prions and their lethal journey to the brain. Nat Rev Microbiol 4: 201-211, 2006.

12. McBride PA, Eikelenboom P, Kraal G, et al: PrP protein is associated with follicular dendritic cells of spleens and lymph nodes in uninfected and scrapie-infected mice. J Pathol 168: 413-418, 1992.

13. Hill AF, Butterworth RJ, Joiner S, et al: Investigation of variant Creutzfeldt-Jakob disease and other human prion diseases with tonsil biopsy samples. Lancet 353: 183-189, 1999.

14. Maignien T, Shakweh M, Calvo P, et al: Role of gut macrophages in mice orally contaminated with scrapie or BSE. Int J Pharm 298: 293-304, 2005.

15. Aucouturier P, Carp RI, Carnaud C and Wisniewski T: Prion diseases and the immune system. Clin Immunol 96: 79-85, 2000.

16. Bueler H, Fischer M, Lang Y, et al: Normal development and behaviour of mice lacking the neuronal cell-surface PrP protein. Nature 356: 577-582, 1992.

17. Li X, Udagawa N, Takami M, et al: p38 Mitogen-activated protein kinase is crucially involved in osteoclast differentiation but not in cytokine production, phagocytosis or dendritic cell differentiation of bone marrow macrophages. Endocrinology 144: 4999-5005, 2003.

18. Mann R, Mulligan RC and Baltimore D: Construction of a retrovirus packaging mutant and its use to produce helper-free defective retrovirus. Cell 33: 153-159, 1983.

19. Ryder EF, Snyder EY and Cepko CL: Establishment and characterization of multipotent neural cell lines using retrovirus vector-mediated oncogene transfer. J Neurobiol 21: 356-375, 1989.

20. Nitta K, Sakudo A, Masuyama J, Xue G, Sugiura K and Onodera T: Role of cellular prion ptoteins in the function of macrophages and dendritic cells. Protein Pept Lett 16: 239-246, 2009.

21. Kuwahara C, Takeuchi AM, Nishimura T, et al: Prions prevent neuronal cell-line death. Nature 400: 225-226, 1999.

22. Wu G, Nakajima K, Takeyama N, et al: Species-specific antiapoptotic activity of cellular prion protein in a mouse PrP-deficient neuronal cell line transfected with mouse, hamster and bovine Prnp. Neurosci Lett 446: 11-15, 2008.

23. Nishimura T, Sakudo A, Hashiyama Y, et al: Serum withdrawalinduced apoptosis in ZrchI prion protein (PrP) gene-deficient neuronal cell line is suppressed by PrP, independent of Doppel. Microbiol Immunol 51: 457-466, 2007.

24. De Almeida CJ, Chiarini LB, Da Silva JP, et al: The cellular prion protein modulates phagocytosis and inflammatory response. J Leukoc Biol 77: 238-246, 2005.

25. Mangé A, Milhavet O, Umlauf D, Harris D and Lehmann S: PrP-dependent cell adhesion in N2a neuroblastoma cells. FEBS Lett 514: 159-162, 2002. 